\title{
Study on the Development of Biogas Fertilizer in Rural China
}

\author{
Xiaoxia Wu \\ School of North China Electric Power University, Baoding 071000, China. \\ 1278685811@qq.com
}

Keywords: Biogas Fertilizer, Biogas - Fertilizer - Agriculture - Sell, Ecological Agriculture, Industrial Chain, Industrial Chain.

\begin{abstract}
In this paper, based on the investigation and analysis of the present situation of biogas fertilizer application in rural areas of China, it is concluded that the main reason for the development of biogas fertilizer are the lack of understanding of biogas manure and the limited production of biogas manure. On this basis, this paper has put forward a new way of comprehensive utilization of biogas fertilizer, namely: "biogas - fertilizer - agriculture - sell" four cycle development of industrial chain. This method not only reasonably and effectively solved the problem of straw burning, but also helps to control the environmental pollution such as haze, and it is highly economical, feasible and easy to popularize.
\end{abstract}

\section{Introduction}

Since the 21st century, the contradiction between population, resources and environment has become increasingly prominent, and China has limited farmland to meet the food needs of the general public. The potential for increasing the availability of arable land to address the food problem is limited, and the only way is to increase the grain production per unit area of land. Fertilizer on the crop yield has been widely recognized. The increase in the amount of fertilizer can increase the grain yield per unit area, but due to unreasonable application, it has brought serious harm to the natural environment. However, biogas fertilizer fermented by the crop straw and human, animal manure and other raw materials possesses comprehensive nutrients, which contains a lot of nitrogen, phosphorus, potassium and a variety of amino acids, humic acid and other organic matter and a variety of trace elements. This fertilizer has a positive effect on improving soil physical and chemical properties and improving the yield and quality of agricultural products, and it is a very good organic fertilizer source. The extensive use of biogas fertilizer in agricultural cultivation will greatly help to alleviate the haze in China. Unfortunately, the current biogas production technology in China has not been widely promoted, biogas production is limited, and biogas project is of low economic efficiency. Given all these reasons, the study of an efficient and environmentally friendly biogas comprehensive application development model is far-reaching.

\section{Current Situation and Existing Problems of Biogas Fertilizer in Rural China}

In order to understand the utilization of biogas fertilizer in China and to explore the development potential of biogas manure, this paper has done a lot of questionnaires before writing and interviewed the head of the biogas company face to face. These surveys and interviews show that the current biogas application model has the following problems:

(1) At present, in addition to individual biogas have biogas processing technology, the biogas slurry from majority of biogas enterprises and small biogas project cannot be used twice. The biogas company's economic benefits are not ideal. A large number of biogas slurry is still open piled up, resulting in serious air pollution and increasing the local haze weather, even caused water pollution. The phenomenon of straw burning in China's rural areas is still common because many farmers do not have proper way to deal with them, deteriorating the environment.

* It can be seen that the problem of straw treatment is imminent, a scientific reasonable, and 
economical treatment will be helpful to solve the social problem of straw burning

(2) Traditional fertilizers is still greatly used in the current Chinese agriculture, and fertilizer prices are generally high, it is a small expenditure for rural families.

* This shows that the more environmentally friendly fertilizer has a great potential for development and market prospects.

(3) The current biogas processing, production, storage and other processes have reached a mature level, but biogas fertilizer has not yet vigorously promoted. The fact that the use of biogas manure can increase the quality of agricultural products, reduce environmental pollution is also recognized by the academic community. However, according to the survey results, $38.8 \%$ of residents are willing to use biogas fertilizer for crops, while $61.2 \%$ of the villagers are reluctant to use biogas for crops. The extensive use of biogas man has been hampered.

* The important reason that biogas man cannot be widely used is that a majority of farmers understand it less. Due to the habit of long-term use of fertilizer is difficult to quickly change, most of the farmers tend to continue to use fertilizer, rather than easily accept new things they do not know. They have a psychological distrust to new things. Therefore, we need popularize the relevant knowledge of biogas fertilizer for farmers, and teach them the scientific basis that it can replace the chemical fertilizer as well as the specific use of biogas manure.

(4) The greatest constraints limited the promotion of biogas fertilizer is production limit. But the current biogas production is mainly determined by the size of the biogas project. In the case of a certain amount of biogas fertilizer, how to effectively use biogas fertilizer is a question worth thinking about.

* On the one hand, the promotion of biogas fertilizer needs the support of all parties to expand the scale of biogas projects, thereby increase the production of biogas fertilizer to encourage the promotion of biogas fertilizer. On the other hand, we need to explore a scientific and efficient comprehensive application model of biogas fertilizer in order to improve the utilization of biogas manure, and produce higher economic benefits.

(5) For now, most residents do not know the concept of green food. In the case of fuzzy ambitions, refusing to buy green food is mainly due to high prices.

* First of all, China need to popularize the concept of green food. Second, few manufacturers produce green food in China, which leads to the high cost of green food than the general food. Given these, the biogas companies can directly use their own biogas fertilizer for crop cultivation. This approach will greatly reduce the cost of green food and promote low market price of green food, which is a very high economic efficiency and good feasibility choice.

(6) Chinese government requires biogas project owns the corresponding treatment of biogas residue, biogas slurry, but there is nocorresponding subsidy policy for biogas fertilizer, which makes the promotion of green ecological agriculture development and the formation of "gas - fertilizer agricultural - sell" four cycle development model limited.

* The vigorous development of biogas fertilizer requires the support of the government and other sectors of society.

\section{Development of New Biogas Fertilizer Comprehensive Utilization}

According to the problems mentioned above, in order to promote the biogas fertilizer, improve the utilization rate of biogas manure and the economy of biogas project, as well as solve the problem of straw burning, you can have the following development ideas:

(1) Broaden residents and farmers' understanding channels of biogas fertilizer, deepen the understanding of biogas and organic agriculture.

At present, the biogas fertilizer and organic agriculture are basically carried out through the enterprise, but the purpose of corporate propaganda is only to promote their own, small-scale development. So its spending on publicity is limited and cannot make a wide range of residents and even all the people understand the biogas fertilizer and organic agriculture. Therefore, it is impossible for enterprises to invest much for ensuring a certain profit, which in turn restricts the development of 
biogas fertilizer with great social value and further hinders the vigorous development of ecological agriculture. To sum up, the government should increase the biogas hygiene and promote the knowledge of biogas and ecological agriculture through its convenient publicity channels and platforms, such as the media, the distribution of brochures, the opening of exhibition halls, etc. These measurements will help people understand and accept this emerging industry, and further promote the development of biogas and ecological agriculture.

(2) Biogas companies should continue to explore and improve the relevant technology, reduce costs and improve product quality, and finally establish a "gas - fertilizer - agricultural - sales" recycling industry chain.

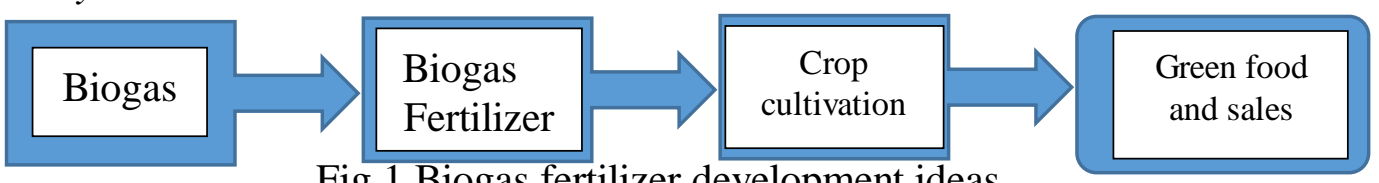

Fig.1 Biogas fertilizer development ideas

The government's strong advocacy and policy support will be conducive to the development of biogas and organic agriculture in the initial stages. But these support are limited and phased. If the relevant enterprises want to maintain long-term market competitiveness, it is necessary to use the government to provide an enabling environment to enhance and improve the industry's technical and management standards, and improve product quality, reduce product costs, and ultimately form a large-scale industrial chain and consumption group.

In view of the shortcomings of the traditional biogas application model, we propose a new biogas fertilizer application model that fully compensates for above shortcomings, namely, producing biogas by pure straw, then produce biogas fertilizer by biogas slurry, and biogas fertilizer will be widely used in agricultural products and forms ecological agriculture, finally standardize, batch produce, processing, sells green agricultural products. Agricultural products to form an ecological agriculture, standardization, batch production, processing and sales of green agricultural products, and ultimately form a "gas - fertilizer - agricultural - sales" all-round closed-loop development model of biogas fertilizer. Thus a self-produced for the integrity of the ecological agriculture industry chain is established. It meets the environmental protection and achieves high profits, as well as promotes regional economic development, healthy development. Biogas fertilizer and ecological agriculture and will truly make a long and sustained contribution to environmental improvement and people's health.

(3) Chinese government should give appropriate incentives to the biogas industry chain.

At present, the Chinese government has given a certain subsidy policy to the biogas project. But support measures to the biogas fertilize are basically blank. Therefore, besides strengthening the publicity, the government should also give biogas fertilizer and related ecological agriculture industry-related policy support. Through publicity, we can let more people understand biogas and ecological agriculture. But the market rules tell us that only when its cost is low within the acceptable range to the people and farmers, will it really have a place in the market. In the current conditions, biogas and ecological agriculture is not enough to achieve this level, so the government needs to introduce some relevant incentives to encourage the use of biogas fertilizer. For example: give tax relief to the biogas fertilizer and eco-agriculture enterprises; limit the use of the traditional fertilizer on land area, urge the traditional fertilizer manufacturers to transform to biogas and ecological agriculture direction. With these incentives, biogas and ecological agriculture will accelerate the development and its related concepts and products will gradually become popular.

\section{Summary}

This paper comprehensively collected the current application of biogas fertilizer in China, and found that there are obstacles to the development of biogas fertilizer, and put forward a new type of biogas fertilizer development ideas for these obstacles. According to the current market orientation, the new development ideas of the economic benefits of considerable, strong environmental protection, to 
promote the harmonious development of man and nature, sustainable development has great help, has a good application prospects.

\section{References}

[1]. Hongli G A O. Effects of biogas fertilizer on output and quality of Brassica chinensis L. and soil quality [J]. Journal of Agro-Environment Science, 2010, 29: p43-47.

[2]. Qingyun Wang,Jiabao Zhang, Bingzi Zhao, Xihai Deng, Xiuli Xin, Shengwu Qin. Effects of different fertilization modes on accumulation and availability of trace elements in typical soil [J]. Journal of Soil Science. 2012 (06); p.26-27.

[3]. Yunyun Xue. Application status and problem analysis on biomass in the application of vegetables. Master doctoral thesis. Northwest University of Agriculture and Forestry Science and Technology. China.2013, p16.

[4]. Zongxiang Guan. Application and promotion of "Four in one" energy ecological model technology [A]. Selection of Seminar on Rural Biogas Development and Rural Well - off Society Construction[C]. 2003, p.113-115.

[5]. Liu Yang, Yani Ma,Fei Cheng, Jinghua Guo. Application effect and development prospect of biogas fertilizer [J]. Rural science and technology. Vol 24 (2015) No.6, p.52-56. 